\title{
PENGEMBANGAN BUKU SISWA ELEKTRONIK BERBASIS ANDROID PADA MATERI SUHU DAN KALOR UNTUK PERSIAPAN UJIAN NASIONAL SMA/MA
}

\author{
Muhammad Reyza Arief Taqwa ${ }^{(1)}$, Yetti Aprilia Utami ${ }^{(2)}$, Lugy Rivaldo(3), \\ (1), (2) Jurusan Fisika, FMIPA, Universitas Negeri Malang \\ ${ }^{(3)}$ Program Studi Pendidikan Fisika, FKIP, Universitas Jambi \\ Email: (1)reyza.arief.fmipa@um.ac.id, ${ }^{(2)}$ apriliayetti@yahoo.com, \\ (3)lugyrivaldo@unja.ac.id
}

\begin{tabular}{l}
\hline Tersedia Online di \\
\hline http://www.jurnal.unublitar.ac.id/ \\
index.php/briliant \\
\hline Sejarah Artikel \\
\hline Diterima pada 7 Mei 2019 \\
Disetuji pada 16 Mei 2019 \\
Dipublikasikan pada 22 Mei 2019 \\
Hal. 225-234
\end{tabular}

Kata Kunci:

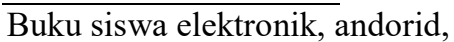
suhu dan kalor

\section{DOI:}

http://dx.doi.org/10.28926/briliant .v3i4.318

\begin{abstract}
Abstrak: Telah dikembangkan Buku Siswa Elektronik berbasis Android untuk persiapan siswa menghadapi Ujian Nasional yang difokuskan pada topik suhu dan kalor. Buku Siswa Elektronik ini memuat 3 bagian pokok yaitu (1) meliputi halaman depan (cover), diskripsi buku, menu tombol dan menu utama; (2) meliputi ringkasan materi, contoh soal, latihan soal, dan paket tryout; (3) meliputi profil pengembang, dan daftar rujukan. Pengembangan ini menggunakan model 4D namun belum mencapai tahap deseminate. Buku yang telah dikembangkan kemudian divalidasi oleh tim ahli dan diuji keterbacaan pada 15 siswa kelas XI MIA 1 SMAN 2 Malang. Hasil analisis data yang diperoleh disimpulkan bahwa buku siswa elektronik adalah buku yang layak dengan tingkat kevalidan 3,88 dan keterbacaan buku sebesar 94,5\%.
\end{abstract}

\section{PENDAHULUAN}

Ujian Nasioanal adalah kegiatan pengukuran capaian siwa terhadap mata pelajaran tertentu berdasarkan Standar Kompetensi Lulusan. Standar kualitas Ujian Nasional yang di tetapkan oleh pemerintah mengalami kenaikan setiap tahun, salah satunya adalah penerapan Ujian Nasional Berbasis Komputer atau UNBK (Muntholi'ah, 2013). Hal tersebut semata-mata untuk mewujudkan hakekat belajar yakni tercapainya perubahan perilaku atau kompetensi perserta didik (Taqwa et al, 2015). Akan tetapi naiknya standar tersebut tidak membuat hasil Ujian Nasional meningkat. Dalam tiga terakhir hasil Ujian Nasional bahkan menurun secara signifikan. Berdasarkan data dari Kementrian Pendidikan dan Kebudayaan (Kemendikbud) mencatat bahwa nilai rata-rata Ujian Nasional fisika dalam tiga periode tahun terakhir turun sebanyak $-5,35$.

Jika meninjau dari materi fisika, suhu dan kalor adalah topik yang selalu diujikan dalam Ujian Nasioanl. Namun sayanganya suhu dan kalor menjadi materi yang tidak di sukai siswa karena sulit (Nova et al, 2016). Sifatnya yang abstrak menimbulkan banyak konsep alternatif pada siswa sehingga konsep dasar yang penting justru menjadi tidak dikuasai (Aryani et al, 2016). Selain itu Sutriyono (2017) menyatakan bahwa minat dan belajar siswa suhu dan kalor masih sangat 
rendah. Padahal tingkat soal untuk Ujian Nasional akan semakin bertambah. Kemendikbud telah memastikan bahwa akan menggunakan tipe soal HOTS untuk ujian tahun depan, naik hingga $75 \%$. Disi lain, sebagai penunjang belajar mandiri sebagian besar siswa belum menumukan buku penunjang belajar yang tepat (Lembah et al, 2012). Selain itu, sering kali siswa tidak mempelajari dan mengevaluasi buku yang telah mereka beli. Artinya tingkat minat belajar siswa terhadap buku yang ada saat ini sebagai inovasi, para pengembang mulai melakukan pembaharuan buku konvensional menjadi buku elektronik atau e-book.

Buku elektronik di buat dengan mengubah tampilan buku ke dalam format digital. Terdapat banyak sekali format yang dapat dimanfaatkan oleh pengembang, salah satu yang terbaik adalah format dengan ekstensi .apk atau aplikasi. Wikipedia dalam artikelnya Comparison of Ebook formats menjelaskan bahwa aplikasi dapat memuat piranti-piranti diam maupun bergerak seperti gambar, video, audio, maupun animasi sehingga tampilan dari buku elektronik dapat di kemas dengan interaktif. Di dalam artikel yang sama Wikipedia mengatakan bahwa untuk membaca format aplikasi pada suatu perangkat maka di butuhkan adanya platform. Android adalah platform dengan supporting features yang paling baik karena dapat menerima banyak macam fitur pada perangkat komputer. Buku dalam bentuk aplikasi berbasis android juga di minati oleh siswa karena membuat tampilan media belajar lebih menarik dan fleksibel. Selain itu, e-book perlu dikembangkan karena mampu memecahkan kesulitan visualisasi pembelajaran fisika dan manfaat kepraktisan dalam membawa buku pelajaran khususnya berbasis ICT (Putrawansyah et al, 2016). Namun sayangnya dalam beberapa penelitian, e-book di kembangkan dengan bantuan perangkat lunak Adobe Flash Profesional. Himmah (2017) mengatakan bahwa software Adobe Flash Profesional cukup sulit pelajari karena mengandung bahasa pemrograman sehingga lebih tepat di gunakan oleh pengembang yang sudah memiliki keahlian di bidang Teknologi Informasi dan Komunikasi.

Terdapat software yang mudah di operasikan namun tetap menghasilkan tampilan yang tidak kalah menarik dari software lain, yaitu i-Spring Suite 8. Di dalam iSpring suite 8 terdapat beberapa fitur, salah satunya adalah quiz. Melaui fitur quiz pengembang dapat menciptakan berbagai bentuk latihan soal dengan fasilitas skoring, diantaranya adalah latihan soal diagnostic test dan simulasi tryout. Melaui simulasi tryout siswa dapat berlatih Ujian Nasional Berbasis Komputer seperti sesungguhnya. Selain itu, simulasi tryout mempermudah akses belajar siswa untuk mempersiapkan Ujian Nasional Berbasis Komputer secara lebih matang (Kumalasari et al, 2017).

Berdasarkan kebutuhan-kebutuhan siswa tersebut, diperlukan adanya suatu pengembangan buku persiapan Ujian Nasiobal yang dapat menyajikan konten-konten persiapan Ujian Nasional dengan tampilan berbasis android. Oleh karena itu, kami telah melakukan pengembangan bahan ajar berupa buku elektronik yang akan digunakan siswa dalam mempersiapkan ujian nasional. Pengembangan kami fokuskan pada topik suhu dan kalor. Dalam artikel ini membahas bagaimana hasil expert judgement dari ahli dan pendapat pengguna terhadap produk hasil pengembangan media belajar berupa buku siswa elektronik berbasis Android pada pokok bahasan Suhu dan Kalor dalam rangka persiapan Ujian Nasional (UN) SMA/MA.

226 BRILIANT: Jurnal Riset dan Konseptual Volume 4 Nomor 2, Mei 2019 


\section{METODE}

Penelitian ini mengadaptasi model pengembangan 4-D dari Thiagarajan et al, (1974). Model 4D terdiri dari empat tahap yaitu: 1) Define atau pendefinisian, 2) Design atau perancangan, 3) Develop atau pengembangan. Validasi dilakukan kepada tiga validator yaitu satu dosen fisika UM dan dua guru fisika di SMAN 2 Malang, Sedangkan untuk uji keterbacaan dilakukan oleh 15 siswa kelas XI MIA 1 di SMAN 2 Malang. Instrumen validasi yang digunakan berupa angket penilaian dan saran. Validator melakukan penilaian dengan melihat dari aspek konten, konstruk, dan aspek android. Sementara itu siswa sebagai responden menilai produk dari segi tampilan, bahasa, isi, android, dan motivasi mereka selama menggunakan produk.

Jenis data yang diperoleh berupa data kuantitatif dan data kualitatif. Data kuantitatif di peroleh dari hasil penilaian angka-angka $(4,3,2,1)$ dalam Skala Likert untuk angket validasi, dan angka $(1,0)$ dalam skala Guttman untuk angket keterbacaan. Sedangkan data kualitatif berupa komentar dan saran dari masingmasing validator. Siswa sebagai responden tetap memberikan komentar dan saran. Teknis analisis untuk data kuantitatif dari validator di hitung menggunakan perhitungan rata-rata. Persamaan yang digunakan untuk menghitung nilai rata-rata adalah sebagai berikut.

$$
\bar{X}=\frac{\Sigma x}{n}
$$

Adapun kriteria hasil validitas analisis perhitungan rata-rata yang digunakan dapat dilihat Tabel 1.

Tabel 1. Tabel kriteria hasil validasi produk oleh validator

\begin{tabular}{cc}
\hline Rata-rata & Kriteria validitas \\
\hline $3,26-4,00$ & Valid / tanpa revisi \\
\hline $2,51-3,52$ & Valid / revisi \\
\hline $1,76-2,50$ & Kurang valid / dengan revisi \\
\hline $1,00-1,75$ & Tidak valid / dengan revisi \\
\hline
\end{tabular}

(Sumber: Arikunto, 2006)

Sedangkan teknik analisis yang digunakan pada uji keterbacaan menggunakan perhitungan persentase sebagai berikut.

$$
\mathrm{NP}=\frac{\sum R}{\sum S M} \times 100 \%
$$

Berdasarkan hasil yang diperoleh maka simpulan terkait keterbacaan produk akan dikelompokkan menjadi beberapa kriteria. Adapun kriteria hasil keterbacaan analisis perhitungan persentase yang digunakan dapat dilihat Tabel 2. 
Tabel 2. Tabel kriteria hasil keterbacaan produk oleh siswa

\begin{tabular}{cc}
\hline Rata-rata & Kriteria validitas \\
\hline $76 \%-100 \%$ & Terbaca \\
\hline $51 \%-75 \%$ & Cukup Terbaca \\
\hline $26 \%-51 \%$ & Kurang Terbaca \\
\hline $10-25 \%$ & Tidak Terbaca \\
\hline
\end{tabular}

\section{HASIL}

\section{Hasil Pengembangan Produk}

Deskripsi produk memberikan informasi terkait Buku Siswa Elektronik secara lebih detail, yang akan dijelaskan dalam bentuk diskripsi mengenai bagianbagian penting dalam buku elekronik siswa, diantaranya sampul depan, petunjuk penggunaan buku, mengenal tombol besarta fungsinya, menu utama, dan isi. Isi berisi KD, kisi-kisi UN, peta konsep, ringkasan materi, contoh soal, dan latihan soal dengan diagnostic-test, paket try out, kunci jawaban dan daftar rujukan. Produk akhir dari penelitian dan pengembangan ini adalah aplikasi android berupa Buku Siswa Elektronik yang memuat 3 bagian pokok buku yaitu Bagian I meliputi halaman depan (cover), diskripsi buku, menu tombol dan menu utama, selanjutnya Bagian II meliputi ringkasan materi, contoh soal, latihan soal, dan paket tryout, dan yang terakhir bagian III meliputi profil pengembang, dan daftar rujukan. Beberapa contoh tampilan hasil produk yang telah dikembangkan ditunjukkan oleh Gambar 1.

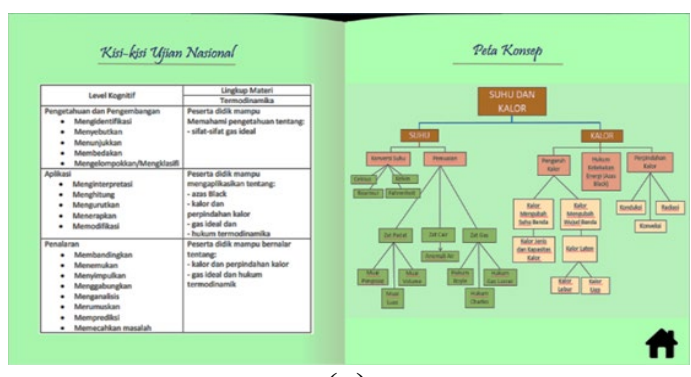

(a)

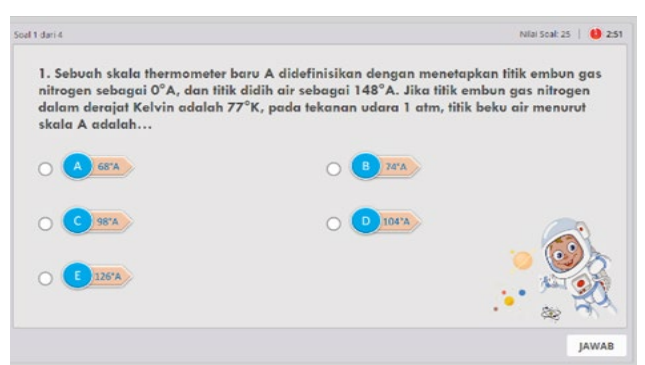

(b)

Gambar 1. (a) Tampilan Kompetensi Dasar dan Peta Konsep, (b) Tampilan Contoh Soal Try Out

\section{Hasil Validasi Ahli dan Uji Coba Terbatas}

Validasi bertujuan untuk mengetahui kelayakan produk secara menyeluruh (Wulandari \& Purwanto, 2017), baik dari segi konten, konstruk, maupun aspek android. Hasil validasi produk oleh dosen dan guru dari segi konten, konstruk, disajikan pada Tabel 1 . 
Tabel 1 Rekapitulasi Hasil Validasi Konten oleh Validator

\begin{tabular}{|c|c|}
\hline Aspek & Sub bab I (Suhu) \\
\hline Konten & 3,90/Valid \\
\hline Konstruk & 3,79/Valid \\
\hline Aspek Android & 3,96/Valid \\
\hline Rata-rata/ kriteria & 3,88/Valid \\
\hline
\end{tabular}

Hasil analisis validasi konten Buku Siswa Elektronik (Tabel 1) diperoleh nilai rata-rata sebesar 3,90 yang artinya jika dilihat dari segi isi buku siswa elektronik memiliki kriteria valid/tanpa revisi. Selanjutnya berdasarkan hasil analisis validasi konstruk diperoleh nilai rata-rata sebesar 3,79 yang artinya jika dilihat dari segi tata letak/tampilan buku siswa elektronik memiliki kriteria valid/tanpa revisi. Begitu juga untuk hasil analisis validasi oleh validator dari aspek android diperoleh nilai rata-rata sebesar 3,96 yang artinya memiliki kriteria valid/tanpa revisi. Dari ketiga hasil tersebut jika di hitung secara total diperoleh nilai rata-rata akhir sebesar 3,88 .

Setelah mengetahui hasil validasi, produk di lakukan revisi atas dasar komentar dan saran dari validator. Beberapa bagian yang di revisi adalah tombol, bahasa, dan beberapa gambar aniamsi pendukung. Selanjutnya produk siap di lakukan uji coba keterbacaan kepada siswa untuk mengetahui tingkat keterbacaan produk. Hasil menunjukkan bahwa siswa setuju bahwa pada beberapa aspek yang di tanyakan pada angket. Rekapitulasi hasil uji keterbacaan buku oleh siswa ditunjukkakn Tabel 2.

Tabel 2. Rekapitulasi Hasil Uji Keterbacaan Buku oleh Siswa

\begin{tabular}{lc}
\hline \multicolumn{1}{c}{ Aspek } & Persentase \\
\hline Tampilan & $91,1 \%$ \\
Bahasa & $100 \%$ \\
Materi, soal, dan tryout & $96,67 \%$ \\
Android \& instalasi & $86,67 \%$ \\
Motivasi & $100 \%$ \\
\hline Rata-rata & $\mathbf{9 4 , 5 \%}$ \\
\hline
\end{tabular}

Berdasarkan Tabel 2 dapat dilihat bahwa rata-rata skor uji keterbacaan oleh siswa adalah 94,5\% yang menunjukkan bahwa buku elektronik merupakan media yang dapat terbaca dengan baik. Adapun rincian dari skor masing-masing aspen yakni aspek tampilan dengan persentase 91,1\% , aspek bahasa dengan persentase $100 \%$, aspek materi, soal dan tryout dengan persentase $96,67 \%$, aspek android dan instalasi dengan persentase $86,67 \%$, dan aspek motivasi dengan persentase $100 \%$.

\section{PEMBAHASAN}

Hasil validasi oleh tim ahli diperoleh rata-rata tiap kriteria sebesar 3,88. Nilai rata-rata tersebut masuk dalam kategori pertama yang artinya buku siswa elektronik adalah valid dari segi isi, tata letak, dan juga aspek android. Hasil penelitian tersebut relevan dengan penelitian yang di lakukan oleh (Maulana, 
2014) yang juga mengembangkan ebook berbasis android. Dalam penelitianya di peroleh hasil validasi buku sebesar 3,375 dengan kriteria valid tanpa revisi. Namun begitu ebook yang di kembangkan tetap di lakukan revisi berdasarkan saran dan komentar dari validator.

BNSP menyebutkan bahwa buku teks memiliki kriteria tertentu untuk berbagai aspek seperti kelayakan isi, bahasa yang digunakan dalam buku, penyajian, dan kegrafikan (Irsyada, 2016). Dalam mengembangkan buku elektronik ini, ada beberapa hal yang telah kami upayakan agar pembaca lebih mudah memahami isi buku dan memahami konsep fisika. Pertama, buku siswa elektronik menyajikan materi berdasarkan Kompetensi Dasar dan menyesuaikan dengan kisi-kisi Ujian Nasional dalam bentuk ringkasan point-point penting. Terdapat penambahan animasi untuk mendukung teori dan konsep yang tersaji dengan komposisi yang cukup sehingga menjadikan buku siswa elektronik sebagai buku yang ringkas sajiannya. Selanjutnya jika masuk pada menu utama, maka pembaca akan dimudahkan dengan adanya penomoran pada masing-masing sub menu. Dengan begitu pembaca dapat menggunakkan buku secara runtut untuk mendapatkan hasil yang maksimal melalui petunjuk yang terorganisir. Dan yang terakhir adalah komponen didalam buku siswa elektronik, di mana telah mencakup aspek yang luas mulai dari sajian kompetensi dasar hingga paket-paket tryout yang menyesuaikan kebutuhan target pembaca atau siswa yang akan melaksanakan Ujian Nasional. Keringkasan sajian pada materi, tampilan menu yang terorganisir, serta aspek komponen buku yang komprehensif cukup menjadikan buku siswa elektronik telah memenuhi kriteria pembuatan e-book yang baik.

Buku siswa elektronik yang dikembangkan telah di uji coba secara terbatas kepada 15 siswa kelas XI MIA 1 di SMAN 2 Malang. Pada uji coba terbatas, siswa dikatakan belum berkompeten dalam memberikan nilai produk, sehingga halam hal ini siswa hanya menyatakan apakah setuju atau tidak dengan pertanyaan yang diberikan oleh pengembang menggunakkan skala guttman yang diadaptasi dari Sugiono tahun 2015 dalam buku Metodologi Penelitian halaman 96. Jika siswa menjawab "Ya" maka artinya setuju dan sebaliknya jika siswa menjawab "Tidak" maka artinya tidak setuju. Berdasarkan data hasil uji coba keterbacaan tersebut, seperti yang ditunjukkan pada tabel 4.7 diperoleh nilai rata-rata presentase sebesar 94,5\%. Menurut Arikunto tingkat keterbacaan 94,5\% masuk dalam kategori pertama artinya buku siswa elektronik dapat terbaca dengan sangat baik.

Sebagaimana dijelaskan, buku elektronik atau e-book telah memenuhi kriteria yang baik maka buku akan menjadi media yang informatif dan kreatif bagi pembaca. Dalam hal ini pembaca adalah siswa sebagai responden uji coba. Jika dihubungkan dengan angket uji coba keterbacaan maka unsur informatif dan kreatif relevan dengan aspek motivasi, dimana didalamnya terdapat dua butir petanyaan yaitu: 1) Apakah dengan menggunakan Buku Siswa Elektronik memudahkan anda belajar materi suhu dan kalor? dan 2) Apakah dengan adanya paket-paket tryout cukup membantu anda latihan belajar stimulasi Ujian Nasional Computer Based Test? Berdasarkan aspek motivasi tersebut, diperoleh nilai presentase rata-rata sebesar $100 \%$, artinya siswa telah dimudahkan dalam memahami informasi (materi suhu dan kalor) didalam buku serta fasilitas (contoh

230 BRILIANT: Jurnal Riset dan Konseptual Volume 4 Nomor 2, Mei 2019 
soal, latihan soal, dan simulasi tryout) yang dikemas dengan treatment-treatment baru yang kreatif.

Kebergunaan buku siswa elektronik ini diharapkan dapat memfasilitasi siswa untuk dapat belajar mandiri. Seperti hal nya modul (Akbarita \& Narendra, 2019) dan quiet book (Untari et al, 2018) yang dikembangkan dapat membantu belajar siswa. Dengan tersedianya latihan soal yang mudah diakses diharapkan dapat membangun pengetahuan siswa secara utuh. Buku elektronik ini menjadi salah satu upaya agar siswa dapat memahami konsep fisika secara utuh sehingga dapat memecahkan persoalan yang dihadapi dengan menggunakan pengetahuan yang relevan (Taqwa \& Pilendia, 2018; Taqwa \& Rivaldo, 2018; Docktor \& Mestre, 2014; Hegde \& Meera, 2012; Maloney, 1990; Ryan et al, 2016; Sajadi et $a l, 2013)$. Selain itu, dengan tersedianya sumber belajar yang mudah diakses diharapkan dapat membangun body of knowledge siswa, agar pengetahuan siswa tidak lagi terpotong-potong (Hammer, 2000; Rivaldo et al, 2018). Sehingga siswa dengan mudah dapat mengaktivasi pengetahuan relevan ketika menghadapi permasalahan. Dengan adanya buku siswa elektronik berbasis android ini, diharapkan dapat mereduksi permasalahan yang umum terjadi yakni kegagalan siswa dalam menjawab persoalan fisika sering kali bukan karena tidak memiliki pengetahuan melainkan gagal dalam mengaktivasi pengetahuan (Afwa et al, 2016; Taqwa \& Faizah, 2016).

\section{KESIMPULAN}

Produk akhir dari penelitian dan pengembangan ini adalah aplikasi android berupa Buku Siswa Elektronik yang memuat 3 bagian pokok buku yaitu Bagian I meliputi halaman depan (cover), diskripsi buku, menu tombol dan menu utama, selanjutnya Bagian II meliputi ringkasan materi, contoh soal, latihan soal, dan paket tryout, dan yang terakhir bagian III meliputi profil pengembang, dan daftar rujukan. Buku Siswa Elektronik adalah buku yang layak dengan tingkat kevalidan 3,88 dan keterbacaan buku sebesar 94,5\%.

\section{SARAN}

Saran ketika mengembangkan Buku Siswa Elektronik atau jenis e-book lainnya adalah mengetahui kriteria pembuatan e-book yang baik dan memahami langkah-langkah penyusunan e-book yang benar. Saran untuk penelitian lain adalah pengembangan produk ini dapat dilakukan dengan menguji efektifitas terhadap penguasaan konsep dan peningkatan motivasi belajar siswa menuju pelaksanaan Ujian Nasional.

\section{DAFTAR RUJUKAN}

Afwa, I. L., Sutopo, \& Latifah, E. (2016). Deep learning question untuk meningkatkan pemahaman konsep fisika. Jurnal Pendidikan: Teori, Penelitian, Dan Pengembangan, 1(3), 434-447.

Akbarita, R., \& Narendra, R. (2019). Pengembangan modul pembelajaran berbasis masalah untuk membantu meningkatkan kemampuan penalaran siswa SMK pada materi fungsi, persamaan fungsi linier dan fungsi kuadrat. Jurnal Briliant: Jurnal Riset Dan Konseptual, 4(1), 2-5. 
Arikunto, S. (2006). Metode Penelitian Kualitatif. Jakarta: Bumi Aksara.

Aryani, A. A. S., Handayanto, S. K., \& Wisodo, H. (2016). Penguasaan Konsep Siswa SMA pada Materi Suhu dan Kalor. In Pros. Semnas Pend IPA Pascasarjana UM (Vol. 1, pp. 1-5).

Docktor, J. L., \& Mestre, J. P. (2014). A Synthesis of Discipline-Based Education Research in Physics. Physical Review Special Topic - Physics Education Research, 1-148.

Hammer, D. (2000). Student resources for learning introductory physics. American Journal of Physics, 68(S1), S52-S59. https://doi.org/10.1119/1.19520

Hegde, B., \& Meera, B. (2012). How do they solve it? An insight into the learner ' $\mathrm{s}$ approach to the mechanism of physics problem solving. Physics Education Research, 010109, 1-9. https://doi.org/10.1103/PhysRevSTPER.8.010109

Himmah, F. M. (2017). Pengembangan Multimedia Interaktif Menggunakan ISpring 8 Sub Materi Zat Adektif Untuk Meningkatkan Belajar Siswa SMP Kelas VIII. E-Journal Unesa, (2), 73-82.

Irsyada, R. (2016). Analisis isi dan kaleyakan penyajian buku sekolah elektronik (BSE) mata pelajaran penjasorkes kelas 2 Sekolah Dasar. Journal of Physical Education, Health, and Sports, 3(2), 121-126.

Kumalasari, E., Erika, \& Mustikasari, D. (2017). Aplikasi Tryout Ujian Online untuk SMA / SMK Sederajat ( Online Examination Tryout Application for Senior and Vocational High School Students ). Jurnal Edukasi, 4(3), 1-5.

Lembah, G., Tellu, A. T., \& Mahpudz, A. (2012). Analisis kebijakan hasil ujian nasional SMA/MA untuk memetakan tingkat kompetensi siswa dan mutu penyelenggaraan pendidikan di provinsi Sulawesi Tengah. Kreatif, 15(1), 115.

Maloney, D. P. (1990). Forces as interactions. The Physics Teacher, 28(1990), 386. https://doi.org/10.1119/1.2343080

Maulana, Z. B. (2014). Rancangan bangun aplikasi ebook berbasis android sebagai media pembelajaran mengopersaikan sistem pengendali elektromagnetik untuk siswa menengah kejuruan DR. Tjipto Semarang. Edu Elektronika Journal, 5(2), 27-34.

Muntholi'ah. (2013). Ujian Nasional, Dulu , Kini dan yang Akan Datang: Tinjauan Normatif. Jurnal Pendidikan Islam, 7(1), 161-180.

Nova, A. R., Parno, \& Handayanto, S. K. (2016). Pengembangan instrumen asesmen penguasaan konsep tes testlet pada materi suhu dan kalor. Jurnal 
Pendidikan: Teori, Penelitian, Dan Pengembangan, 1(6), 1197-1203.

Putrawansyah, F., Zulkardi, \& Sardianto, M. S. (2016). Pengembangan Digital Book Berbasis Android Materi Perpindahan Kalor Di Sekolah Menengah Atas. Indonesian Journal on Networking and Security, 5(4), 39-48.

Rivaldo, L., Taqwa, M. R. A., \& Taurusi, T. (2018). Resources Siswa SMA tentang Konsep Gaya Archimedes. Jurnal Pendidikan Fisika Universitas Muhammadiyah Makassar, 6(3), 251-258. Retrieved from http://journal.unismuh.ac.id/index.php/jpf/issue/view/114/showToc

Ryan, Q. X., Frodermann, E., Heller, K., Hsu, L., \& Mason, A. (2016). Computer problem-solving coaches for introductory physics: Design and usability studies. Physical Review Physics Education Research, 12(1), 1-17. https://doi.org/10.1103/PhysRevPhysEducRes.12.010105

Sajadi, M., Amiripour, P., \& Rostamy-Malkhalifeh, M. (2013). The Examinig Mathematical Word Problems Solving Ability under Efficient Representation Aspect. Mathematics Education Trends and Research, 2013, 1-11. https://doi.org/10.5899/2013/metr-00007

Sutriyono, S. (2017). Efektivitas pembelajaran suhu dan kalor dengan strategi group investigation berbantuan CD interaktif kelas X. Jurnal Penelitian Pembelajaran Fisika, 3(1), 59-73. https://doi.org/10.26877/jp2f.v3i1/april.387

Taqwa, M. R. A., Astalini, \& Darmaji. (2015). Hubungan Gaya Belajar Visual, Auditorial, Dan Kinestetik Dengan Hasil Belajar Siswa Pada Materi Dinamika Rotasi Dan Kesetimbangan Benda Tegar Kelas XI IPA SMAN SeKota Jambi. Prosiding Seminar Nasional Sains Dan Pendidikan Sains, (2009), 220-227.

Taqwa, M. R. A., \& Faizah, R. (2016). Perlunya Program Resitasi untuk Meningkatkan Kemampuan Mahasiswa dalam Memahami Konsep Gaya dan Gerak. Pros. Semnas Pend. IPA Pascasarjana UM, 12(1), 365-372.

Taqwa, M. R. A., \& Pilendia, D. (2018). Kekeliruan Memahami Konsep Gaya, Apakah Pasti Miskonsepsi? Jurnal Inovasi Pendidikan Fisika Dan Integrasinya, 01(02), 1-12.

Taqwa, M. R. A., \& Rivaldo, L. (2018). Kinematics Conceptual Understanding : Interpretation of Position Equations as A Function of Time. Jurnal Pendidikan Sains, 6(4), 120-127.

Thiagarajan, S., Semmel, D. S., \& Semmel, M. I. (1974). Instructional development for training teachers of exceptional children: A sourcebook. Indiana University. Indiana: Indiana Unicersity. https://doi.org/10.1016/0022-4405(76)90066-2 
Untari, M. F. A., Budiman, M. A., \& Kusumaningrum, D. (2018). Pengembangan Media Quiet Book untuk pembelajaran tematik keluargaku sekolah dasar kelas I. Jurnal Briliant: Jurnal Riset Dan Konseptual, 3(4), 376-384.

Wulandari, Y., \& Purwanto, W. E. (2017). Kelayakan aspek materi dan media dalam pengembangan buku ajar sastra lama. Jurnal Gramatika, 3(2), 162172. 